\title{
Relationships among Obesity, Sarcopenia, and Osteoarthritis in the Elderly
}

\author{
Woo Sung Jin' ${ }^{1}$, Eun Jung Choi ${ }^{1}{ }^{*}$, Sang Yeoup Lee ${ }^{2}$, Eun Jin Bae', Taeck-Hyun Lee', Juwon Park ${ }^{1}$ \\ ${ }^{1}$ Department of Family Medicine, Daedong Hospital, Busan; '2Department of Medical Education, Pusan National University School of Medicine, Department of Family \\ Medicine, Pusan National University Yangsan Hospital, Busan, Korea
}

Background: The present study examined the correlations between obesity, sarcopenia, and osteoarthritis in Korea's elderly population.

Methods: A cross-sectional analysis of 1,865 and 1,769 respondents with knee osteoarthritis and lumbar spondylosis, respectively, was performed by using data from the 2010 and 2011 Korea National Health and Nutrition Examination Survey. Obesity was defined as a body mass index of $\geq 25 \mathrm{~kg} / \mathrm{m}^{2}$; osteoarthritis, as a Kellgren/Lawrence grade of $\geq 2$; and sarcopenia, as an appendicular skeletal muscle mass (ASM; ASM/weight $\times 100$ ) on dualenergy X-ray absorptiometry of two standard deviations below the mean reference value.

Results: The unadjusted and age-adjusted risks of knee osteoarthritis were as follows: 1.88 and 1.92 times greater, respectively, for male subjects with sarcopenic obesity; 6.03 and 7.64 times greater, respectively, for female subjects with non-sarcopenic obesity; and 1.97 and 2.43 times greater, respectively, for female subjects with sarcopenic obesity. The age-and-waist circumference-adjusted risks were 5.88 and 1.80 times greater for the female subjects with non-sarcopenic and sarcopenic obesities, respectively. No statistically significant finding was obtained for lumbar spondylosis.

Conclusion: Obesity and sarcopenia were associated with knee osteoarthritis in the elderly subjects. The risk of knee osteoarthritis was greater in the male subjects with sarcopenic obesity than in the male subjects with nonsarcopenic obesity. In the female subjects, the risk of knee osteoarthritis was high in both obesity groups. Further research to explain the sex-related difference in knee osteoarthritis risk based on body composition will be beneficial.

Key words: Obesity, Sarcopenia, Osteoarthritis, Knee, Lumbar spondylosis

Received March 17, 2016

Reviewed April 4, 2016

Accepted May 16, 2016

*Corresponding author

Eun Jung Choi

(ii)

http://orcid.org/0000-0002-8012-5473

Department of Family Medicine, Daedong Hospital, 187 Chungnyeoldaero, Dongnae-gu, Busan 47737, Korea Tel: +82-51-550-9373

Fax: +82-51-553-7575

E-mail: ej_jump@daum.net

\section{INTRODUCTION}

Obesity is reported to be a major risk factor of functional and physical impairments in the elderly. ${ }^{1}$ In addition, decreased resting metabolic rate accompanying aging is known as a key driver of gradual skeletal muscle mass loss and fat gain. ${ }^{2}$

Sarcopenia is a progressive muscle mass loss associated with aging. In particular, decreased skeletal muscle mass is a prominent change that accompanies aging. ${ }^{3}$ In addition to reduced muscle mass, sarcopenia is characterized by decreased muscle strength and increased fat mass ${ }^{4}$, which can lead to impaired mobility, increased risk of falling, impaired daily function, decreased independence, and shortened life expectancy. ${ }^{5}$

Sarcopenic obesity is sarcopenia accompanied with obesity in the elderly population. Sarcopenic obesity can increase the risk of functional impairment, reduce quality of life, and increase morbidity in the elderly owing to the interaction of the two underlying conditions. ${ }^{6}$ The prevalence of sarcopenia obesity increases among the aged. Sarcopenia obesity increases cardiovascular disorders and insulin resistance, and is highly associated with metabolic syndromes. ${ }^{7,8}$

Copyright (C) 2017 Korean Society for the Study of Obesity

(a) This is an Open Access article distributed under the terms of the Creative Commons Attribution Non-Commercial License (http://creativecommons.org/licenses/by-nc/4.0/) which permits unrestricted non-commercial use, distribution, and reproduction in any medium, provided the original work is properly cited. 
Osteoarthritis (OA) is a condition that commonly affects the elderly. ${ }^{9}$ Although the pathophysiology of OA has not been clearly identified, the association between knee OA and obesity has been clearly identified well. ${ }^{10,11}$ In addition, weight-bearing joints such as the knee joints are reported to be at a greater risk of OA due to the biomechanical effects of surplus weight. ${ }^{12}$ Lumbar spine OA (lumbar spondylosis [LS]) is also known to have various causes. As it is observed in the synovial joint, excess loads on joints is associated with degenerative changes, and osteophytosis and intervertebral disks. ${ }^{13,14}$

The Korean society is rapidly aging. In 2010, Koreans aged $\geq 65$ years made up $11.0 \%$ of the national population, and the figure is projected to increase to $24.3 \%$ by 2030 and to $37.4 \%$ by $2050 .{ }^{15} \mathrm{On}$ the other hand, obesity has also been on a continual increase due to reduction of physical activity caused by Koreans' westernized dietary habits and advances in transportation. ${ }^{16}$ Aging-associated diseases are expected to put a huge socioeconomic burden on the Korean society, a fact that demands effective disease prevention and management strategies.

Of various aging-associated diseases, obesity, sarcopenia, and OA have been recognized as important health issues concerning the elderly population, as the conditions greatly impact the elderly's activities of daily life (ADL) and quality of life (QOL). ${ }^{1,5,17}$ The present study analyzed data from the Korea National Health and Nutrition Examination Survey (KNHANES) to examine the associations between obesity, sarcopenia, and osteoarthritis in the elderly population ( $\geq 65$ years). It was aimed at providing elementary data required for developing effective disease prevention and management programs for the elderly population in Korea.

\section{METHODS}

\section{Study subjects}

The present study used the first- and second-year (2010-2011) data of the fifth Korea National Health and Nutrition Examination Survey (KNHANES V-1 and V-2). Approval for the study was obtained from the research ethics committee of the Korea Center for Disease Control and Prevention (IRB No. 2010-02CON-21-C, 2011-02CON-06-C).

Of 17,476 respondents, 8,958 participated in the first year (2010) and 8,518 participated in the second year (2011) of the fifth KNHANES. Of these respondents, 1,322 were men and 1,754 were women, aged $\geq 65$ years. Of these men and women, 824 men and 1,071 women underwent dual-energy $\mathrm{X}$-ray absorptiometry (DXA), of whom 818 men and 1,062 women underwent knee radiography. Six men and 7 women were excluded because of chronic renal failure, which left 812 men and 1,055 women for the knee OA analysis. Subsequently, 2 additional men were excluded because of incomplete or missing data, which resulted in 810 men and 1,055 women selected for the final subject pool.

On the other hand, 778 men and 1,004 women underwent a lumbar radiography, of whom 6 men and 5 women were excluded because of chronic renal failure. Thus, 772 men and 999 women were finally selected for the LS analysis. Subsequently, 2 additional men were excluded because of incomplete or missing data, which resulted in 770 men and 999 women selected for the study analysis.

The exclusion of men and women with chronic renal failure was based on a previous report that the condition is associated with sarcopenia. $^{18}$

\section{Study methods}

Plain radiography was used for the assessment of knee $\mathrm{OA}$ (plain radiographs, SD3000 Synchro Stand, Accele Ray). The subjects were asked to stand with their bodyweights evenly distributed between two feet for anteroposterior imaging of the patella. The subjects were then asked to rotate at a $90^{\circ}$ from the original standing position with the knee bent at about $30^{\circ}$ for lateral measurement. For the lumbar measurement, the subjects were positioned to maintain lordosis posture, and then anteroposterior and lateral views of $\mathrm{L} 3$ throughL4 were obtained.

For measurement of total fat mass and skeletal muscle mass, DXA was performed (Hologic, Inc., Bedford, MA, USA). For measurement of appendicular skeletal muscle mass (ASM), the Heymsfield method ${ }^{19}$ was used, which is the sum of fat-free soft tissue masses in the limbs.

\section{Definitions and subject classifications}

According to the World Health Organization (WHO) classification of body mass index (BMI) for Asians, obesity was defined as a BMI of $\geq 25 \mathrm{~kg} / \mathrm{m}^{2} .{ }^{20}$ The present study used DXA to measure 
muscle mass. Conforming to the results of a previous Korean study ${ }^{8,21}$, sarcopenia was diagnosed based on the value obtained by dividing the ASM by bodyweight (ASM/weight $\times 100$ ). To estimate the cutoff value for sarcopenia diagnosis, the mean ASM index (ASM/weight $\times 100)$ of healthy young men and women aged 20-39 years and standard deviation (SD) were used. In selecting young sex-matched reference groups of healthy 20 - to 39-year-olds, individuals who had diabetes, stroke, cardiovascular disease, thyroid disease, arthritis, tuberculosis, asthma, chronic obstructive pulmonary disease, hepatocirrhosis, renal disease, and cancer were excluded. Sarcopenia was determined when the measurement was 2SDs below the average of the young sex-matched reference group. ${ }^{22,23}$

Sarcopenic obesity was determined if a subject had both sarcopenia and obesity. The severity of radiographic knee osteoarthritis was assessed with the Kellgren/Lawrence grading system as follows ${ }^{24}$ : grade 0 , normal; grade 1, slight osteophytic lipping; grade 2, definite osteophytes; grade 3, definite osteophytes and marked joint space narrowing; and grade 4, marked joint space narrowing and below-cartilage sclerosis. Knee OA was determined for the subjects with a $K L$ grade of $\geq 2$.

Owing to the absence of an international consensus on the diagnostic criteria for LS, published raw data were used and diagnostic criteria were developed based on Kellgren and Lawrence's criteria. ${ }^{24}$ For the assessment, grade levels of $0-2$ were established based on those developed by Yoshimura et al. ${ }^{25} \mathrm{LS}$ was diagnosed in the presence of at least one lumbar assessed as a KL grade of $\geq 2$.

The subjects were divided into male and female groups, which were subsequently divided into four body composition groups according to the subjects' sarcopenia and obesity statuses, and sarcopenic obesity ( $\mathrm{SO}$ ) status as follows: normal body composition (NO), sarcopenic non-obesity (SP), non-SO (OB), and SO.

\section{Statistical analysis}

One-way analysis of variance was used to process the subjects' demographic data. For post hoc analysis, the Bonferroni method was used, and continuous variables were presented as mean $\pm \mathrm{SD}$.

To examine the correlations among obesity, sarcopenia, and OA, the sampling weight for each survey criterion recommended by the KNHANES and the number of respondents in each survey year were considered. Combined weights were calculated by multiplying the 2010 sampling unit ratio of 192:272 with the 2010 sampling weight and the 2011 sampling unit ratio of 80:272 with the 2011 sampling weight. By using the above-mentioned figures, a logistic regression based on a complex sampling design was performed.

Based on a previous study that found that age-and-waist circumference-based abdominal obesity was pathophysiologically and statistically associated with sarcopenia obesity ${ }^{26}$, age and waist circumference were used as covariates to control the effects on the relationships among obesity, sarcopenia, and OA. Model 1 incorporated only age as a covariate, while model 2 incorporated both age and waist circumference as covariates. Continuous variables were expressed as mean \pm SD. Odds ratios and $95 \%$ confidence intervals (CIs) were calculated, and the statistical significance of group differences based on the reference groups was verified. Statistical significance was determined based on a $P$ value of $<0.05$. Statistical analysis was performed with SPSS version 22.0 (IBM, NY, USA).

\section{RESULTS}

\section{Characteristics of the subjects according to 4 body compositions}

In general, the obesity groups showed a significantly greater body weight, waist circumference, BMI, and total body fat. On the other hand, the sarcopenia groups showed a significantly greater total body fat and significantly lower ASM and ASM index (Tables 1 and 2).

\section{Correlation between knee $\mathrm{OA}$ and body compositions}

Among the male subjects aged $\geq 65$ years, the SO group had an unadjusted odds ratio (OR) of 1.88 (95\% CI, 1.22-2.89) and an age-adjusted OR of 1.92 (95\% CI, 1.23-2.99), indicating a significant increase. However, when adjusted for both age and waist circumference, no significant difference was found (Table 3).

Among the female subjects aged $\geq 65$ years, the OB group had an unadjusted OR (95\% CI) of 6.03 (1.90-19.15), an age-adjusted OR of 7.64 (2.37-24.57), and an age-and-waist circumference-adjusted OR of 5.88 (1.71-20.22), indicating a significant increase. The SO group had corresponding ORs (95\% CI) of 1.97 (1.312.95), 2.43 (1.60-3.69), and 1.80 (1.03-3.12), which indicated a significant increase (Table 3 ). 


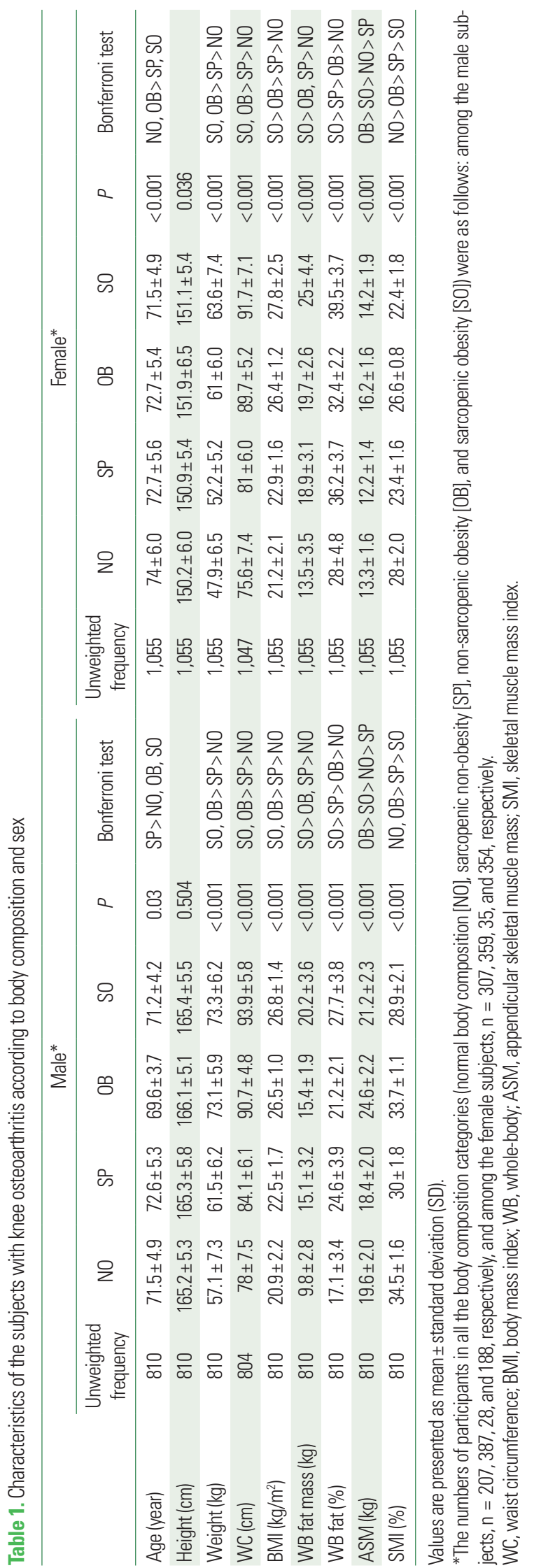

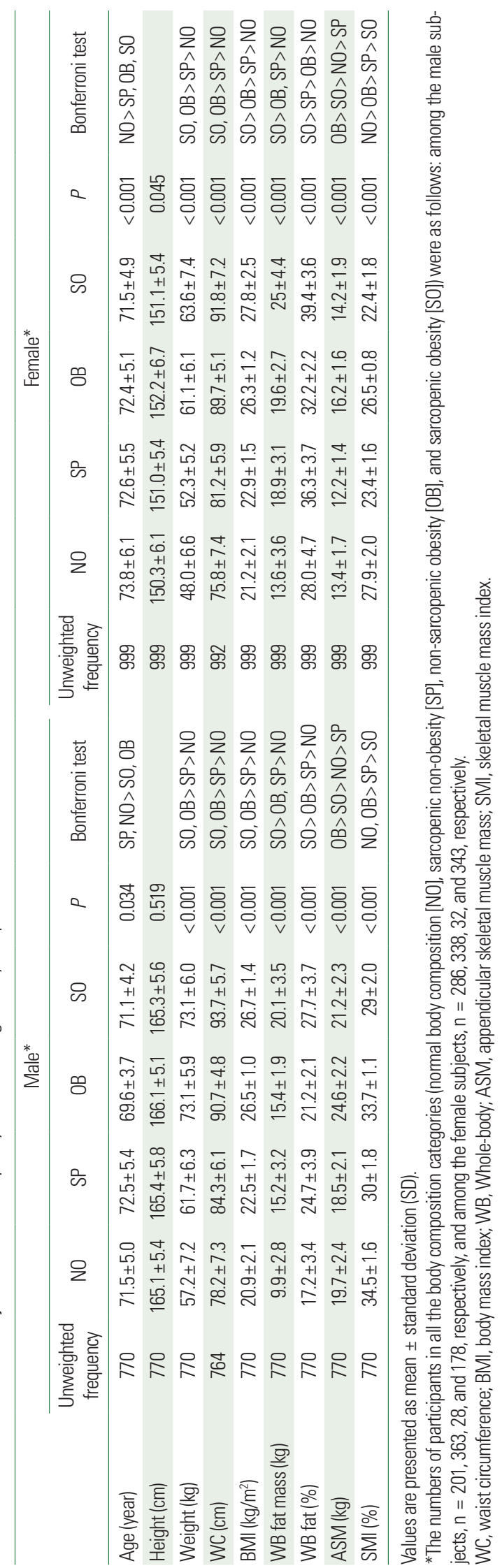


Table 3. Association between radiographic knee osteoarthritis and the 4 body composition categories

\begin{tabular}{|c|c|c|c|c|c|c|c|c|c|c|}
\hline \multirow[b]{2}{*}{ Sex } & \multirow[b]{2}{*}{ Group } & \multicolumn{3}{|c|}{ Crude } & \multicolumn{3}{|c|}{ Model 1} & \multicolumn{3}{|c|}{ Model 2} \\
\hline & & $\begin{array}{l}\text { Unweighted } \\
\text { frequency } \\
\text { (Weighted \%) }\end{array}$ & $\begin{array}{c}\text { OR } \\
(95 \% \text { Cl) }\end{array}$ & $P$ & $\begin{array}{l}\text { Unweighted } \\
\text { frequency } \\
\text { (Weighted \%) }\end{array}$ & $\begin{array}{c}\text { OR } \\
(95 \% \mathrm{Cl})\end{array}$ & $P$ & $\begin{array}{l}\text { Unweighted } \\
\text { frequency } \\
\text { (Weighted \%) }\end{array}$ & $\begin{array}{c}\text { OR } \\
(95 \% \text { Cl) }\end{array}$ & $P$ \\
\hline \multirow[t]{5}{*}{ Male } & NO & $207(28.0)$ & Reference & & $207(28.0)$ & Reference & & 205 (28.1) & Reference & \\
\hline & SP & $387(45.6)$ & $1.23(0.85-1.79)$ & 0.279 & $387(45.6)$ & 1.14 (0.79-1.65) & 0.476 & $383(45.4)$ & 1.00 (0.66-1.53) & 0.989 \\
\hline & $\mathrm{OB}$ & $28(3.2)$ & 1.41 (0.52-3.81) & 0.502 & $28(3.2)$ & $1.54(0.55-4.33)$ & 0.411 & $28(3.3)$ & $1.13(0.37-3.43)$ & 0.832 \\
\hline & SO & $188(23.2)$ & $1.88(1.22-2.89)$ & $<0.05$ & $188(23.2)$ & 1.92 (1.23-2.99) & $<0.005$ & $188(23.3)$ & $1.34(0.70-2.55)$ & 0.379 \\
\hline & Total & 810 & & & 810 & & & 804 & & \\
\hline \multirow[t]{5}{*}{ Female } & NO & $307(30.1)$ & Reference & & $307(30.1)$ & Reference & & $304(30.1)$ & Reference & \\
\hline & SP & $359(33.5)$ & 1.01 (0.69-1.48) & 0.964 & $359(33.5)$ & 1.11 (0.76-1.63) & 0.581 & 356 (33.5) & 0.99 (0.66-1.49) & 0.97 \\
\hline & OB & $35(3.1)$ & $6.03(1.90-19.15)$ & $<0.005$ & $35(3.1)$ & 7.64 (2.37-24.57) & $<0.005$ & $35(3.1)$ & 5.88 (1.71-20.22) & $<0.05$ \\
\hline & SO & $354(33.3)$ & $1.97(1.31-2.95)$ & $<0.005$ & $354(33.3)$ & $2.43(1.60-3.69)$ & $<0.001$ & 352 (33.3) & $1.80(1.03-3.12)$ & $<0.05$ \\
\hline & Total & 1,055 & & & 1,055 & & & 1,047 & & \\
\hline
\end{tabular}

Crude and odds ratios (ORs), and 95\% confidence intervals (95\% CI) were calculated by using the complex-sample logistic regression analysis.

Model 1 was adjusted for age.

Model 2 was adjusted for age and waist circumference.

NO, normal body composition; SP, sarcopenic non-obesity; OB, non-sarcopenic obesity; SO, sarcopenic obesity.

Table 4. Association between radiographic lumbar spondylosis and the 4 body composition categories

\begin{tabular}{|c|c|c|c|c|c|c|c|c|c|c|}
\hline \multirow[b]{2}{*}{ Sex } & \multirow[b]{2}{*}{ Group } & \multicolumn{3}{|c|}{ Crude } & \multicolumn{3}{|c|}{ Model 1} & \multicolumn{3}{|c|}{ Model 2} \\
\hline & & $\begin{array}{l}\text { Unweighted } \\
\text { frequency } \\
\text { (Weighted \%) }\end{array}$ & $\begin{array}{c}\text { OR } \\
(95 \% \mathrm{Cl})\end{array}$ & $P$ & $\begin{array}{l}\text { Unweighted } \\
\text { frequency } \\
\text { (Weighted \%) }\end{array}$ & $\begin{array}{c}\text { OR } \\
(95 \% \text { Cl) }\end{array}$ & $P$ & $\begin{array}{l}\text { Unweighted } \\
\text { frequency } \\
\text { (Weighted \%) }\end{array}$ & $\begin{array}{c}\text { OR } \\
(95 \% \mathrm{Cl})\end{array}$ & $P$ \\
\hline \multirow[t]{5}{*}{ Male } & NO & $201(30.2)$ & Reference & & $201(30.2)$ & Reference & & 199 (30.3) & Reference & \\
\hline & $\mathrm{SP}$ & $363(35.8)$ & $0.88(0.57-1.34)$ & 0.54 & 363 (35.8) & $0.79(0.52-1.20)$ & 0.266 & 359 (35.8) & $0.79(0.50-1.24)$ & 0.306 \\
\hline & OB & $28(6.8)$ & $1.50(0.63-3.59)$ & 0.364 & $28(6.8)$ & $1.69(0.69-4.14)$ & 0.253 & $28(6.9)$ & $1.66(0.61-4.47)$ & 0.319 \\
\hline & SO & $178(27.1)$ & 0.89 (0.58-1.38) & 0.607 & $178(27.1)$ & 0.91 (0.59-1.38) & 0.641 & $178(27.0)$ & $0.89(0.50-1.57)$ & 0.681 \\
\hline & Total & 770 & & & 770 & & & 764 & & \\
\hline \multirow[t]{5}{*}{ Female } & NO & $286(30.2)$ & Reference & & $286(30.2)$ & Reference & & $283(30.2)$ & Reference & \\
\hline & SP & 338 (33.1) & $1.05(0.71-1.54)$ & 0.813 & $338(33.1)$ & $1.14(0.78-1.68)$ & 0.493 & $335(33.1)$ & $0.99(0.67-1.47)$ & 0.955 \\
\hline & $\mathrm{OB}$ & $32(3.0)$ & $1.75(0.65-4.69)$ & 0.266 & $32(3.0)$ & $2.23(0.82-6.07)$ & 0.117 & $32(3.1)$ & $1.56(0.54-4.50)$ & 0.407 \\
\hline & SO & 343 (33.7) & $0.91(0.62-1.35)$ & 0.643 & 343 (33.7) & $1.09(0.71-1.66)$ & 0.692 & 342 (33.7) & $0.72(0.41-1.24)$ & 0.235 \\
\hline & Total & 999 & & & 999 & & & 992 & & \\
\hline
\end{tabular}

Crude and each odds ratios (ORs), and 95\% confidence intervals (95\% CI) calculated by using the complex-sample logistic regression analysis.

Model 1 was adjusted for age.

Model 2 was adjusted for age and waist circumference.

NO, normal body composition; SP, sarcopenic non-obesity; OB, non-sarcopenic obesity; SO, sarcopenic obesity.

\section{Correlations between LS and body compositions}

No significant OR was found for body composition and LS among those aged $\geq 65$ years in both sexes (Table 4 ).

\section{DISCUSSION}

The present study examined the correlations among obesity, sarcopenia, and $\mathrm{OA}$ (knee OA, lumbar OA). The results indicated that in the male $\mathrm{SO}$ group aged $\geq 65$ years, the risk of knee $\mathrm{OA}$ increased significantly both before and after adjusting for age. However, no significant difference was found when no adjustment was made for both age and waist circumference. In other words, waist circumference is a significant influencing factor of knee OA in elderly men.

In the female subjects aged $\geq 65$ years, $\mathrm{SO}$ was found to significantly increase the risk of knee OA. In contrast to their male counterparts, the female subjects with SO had an increased risk of knee $\mathrm{OA}$ even after adjusting for both age and waist circumference. It is interesting that the female $\mathrm{OB}$ group had a significantly increased 
risk of knee OA both before and after adjusting for age, which suggests that obesity itself is highly correlated with knee OA in the elderly female group.

A previous Korean study ${ }^{26}$ examined the association between $\mathrm{SO}$ and knee $\mathrm{OA}$ in individuals aged $\geq 50$ years without discriminating for sex and found that the risk of knee $\mathrm{OA}$ increased in both the $\mathrm{OB}$ and $\mathrm{SO}$ groups when adjusted for age, sex, and waist circumference. However, the present study included sex-discriminated subjects aged $\geq 65$ years, and the risk of knee $\mathrm{OA}$ increased significantly in the female $\mathrm{SO}$ group only, when both age and waist circumference were unadjusted for. In addition, only the OB group of female subjects was found to have a significantly increased risk of knee OA.

It is noteworthy that the female OB group in the present study had a greater OR than the women aged $\geq 65$ years in the $\mathrm{SO}$ group. This may be attributed to the difference in obesity diagnosis criteria between the two studies, which was a BMI of $27.5 \mathrm{~kg} / \mathrm{m}^{2}$ in the reference study and BMI of $25 \mathrm{~kg} / \mathrm{m}^{2}$ in the present study. ${ }^{20,26,27} \mathrm{In}$ other words, owing to the increased prevalence of $\mathrm{SO}$ due to aging $^{22}$, the $\mathrm{OB}$ prevalence decreased and the $\mathrm{SO}$ prevalence increased in the female subjects aged $\geq 65$ years. Therefore, the increased OR does not have significant implications.

The present study did not find a significant correlation between LS and the presence of either obesity or sarcopenia. Considering a previous research that found a positive correlation between obesity and age-associated $\mathrm{LS}^{25,28,29}$, attempting to identify the correlation using ASM as the only criterion for sarcopenia proved hugely limiting. According to a previous study ${ }^{30}$, aging-related changes in body composition vary according to body parts. Based on this finding, incorporating additional indexes that reflect muscle masses surrounding the spine and torso, in addition to the ASM, will help clarify the association with LS.

Recently, the European Working Group on Sarcopenia in Older People suggested an updated definition of sarcopenia and established reduced muscle strength (i.e., muscle strength or performance and functioning) as important diagnostic criteria for the condition, in addition to reduced muscle mass. ${ }^{31}$ Moreover, based on a previous study that found no significant relationship between aging-associated reduction in muscle mass and strength, assessment of muscle quality, in addition to muscle mass, appears to be important in diagnosing sarcopenia. Future studies that incorporate these criteria will clarify the relationship between sarcopenia and OA.

Previous reports indicated that in addition to aging, various other factors such as physical activity, energy, and hormone can affect reduction in skeletal muscle mass and strength. ${ }^{32,33}$ Various adipokines, including leptin, adiponectin, resistin, and visfatin, have been reported to be secreted from fat tissues because of obesity, causing fat cells to infiltrate and inflame the muscles, which results in decreased muscle mass ${ }^{34}$ and articular cartilage catabolism. ${ }^{35}$ Based on this finding, approaching the subject from an endocrinal standpoint appears to be beneficial.

The present study has several limitations. First, skeletal muscle mass was measured with DXA, and the measured values tend to overestimate the total skeletal muscle mass. ${ }^{36}$ As such, for a more accurate assessment of sarcopenia in the future, computed tomography or magnetic resonance imaging are required.$^{37}$ In future studies, in addition to plain radiography, clinical examinations, including physical examination and patient interview for medical history taking to collect information pertaining to knee pain, severity of pain, knee stiffness, and so on in the future studies are needed. Second, because of the nature of this cross-sectional study, identifying a causal relationship or predicting trends over time was difficult. Therefore, a prospective study consisting of a larger number of subjects will be beneficial. Third, because the present study only included data from the KNHANES for assessment of body compositions, the potential for selection bias exists. Finally, sex- and race-related differences in age-related physical composition changes have been reported. ${ }^{30}$ As the present study was limited to examining Koreans aged $\geq 65$ years, a follow-up study is needed to improve its external validity by comparing the results with those derived from other races.

In conclusion, although no association was found between LS and the presence of obesity or sarcopenia, the conditions were found to correlate with knee OA, which varied according to sex. In the male subjects, the SO group was 1.92 times more likely to develop knee $\mathrm{OA}$ than the reference group when age was unadjusted for. In the female subjects, the $\mathrm{OB}$ and $\mathrm{SO}$ groups were 5.88 and 1.80 times more likely to develop knee OA than the reference group when both age and waist circumference were unadjusted for. This sex-related difference suggests that in addition to the mechanical effects ${ }^{12}$ of obesity and bodyweight on the risk of knee OA, sex- 
related difference in body composition may also have an effect.

Aging-related changes in physical composition, which vary according to sex, occur independent from changes in bodyweight. ${ }^{30,38}$ In addition, the obesity index, BMI $\left(\mathrm{kg} / \mathrm{m}^{2}\right)$, does not reflect body fat composition. Even at the same BMI, fat mass greater than skeletal muscle mass poses a greater risk of knee OA than obesity measured based on BMI because fat tissues are endocrinal organs that affect the pathophysiology of knee OA; thus, the endocrinal effect will be more significant. ${ }^{34,35,39}$

Abdominal fat, which accounts for a significant portion of total body fat, is closely related to waist circumference. ${ }^{40}$ Therefore, the sex-related difference in knee $\mathrm{OA}$ is thought to $\mathrm{b}$ e attributable to the sex-related differences in body composition and waist circumference, with the latter accounting for a significant portion of the total body fat. However, the underlying mechanism of these differences has not been clarified yet. Therefore, to elucidate the mechanism of the sex-related differences in knee OA and body compositions, an integrated approach is needed through studies that examine the interplay between potential influencing factors.

Finally, obesity and sarcopenia assessment methods that are better suited for use in Korea, clearer diagnostic criteria, and early screening will be beneficial. On this note, preventive and treatment methods that incorporate exercise and diet are needed.

\section{CONFLICTS OF INTEREST}

The authors have no conflicts of interest to declare.

\section{REFERENCES}

1. Jensen GL, Friedmann JM. Obesity is associated with functional decline in community-dwelling rural older persons. J Am Geriatr Soc 2002;50:918-23.

2. St-Onge MP, Gallagher D. Body composition changes with aging: the cause or the result of alterations in metabolic rate and macronutrient oxidation? Nutrition 2010;26:152-5.

3. Rosenberg IH. Summary comments. Am J Clin Nutr 1989; 50:1231-3.

4. Morley JE, Baumgartner RN, Roubenoff R, Mayer J, Nair KS. Sarcopenia. J Lab Clin Med 2001;137:231-43.
5. Baumgartner RN, Koehler KM, Gallagher D, Romero L, Heymsfield SB, Ross RR, et al. Epidemiology of sarcopenia among the elderly in New Mexico. Am J Epidemiol 1998;147: 755-63.

6. Prado CM, Wells JC, Smith SR, Stephan BC, Siervo M. Sarcopenic obesity: a critical appraisal of the current evidence. Clin Nutr 2012;31:583-601.

7. Chin SO, Rhee SY, Chon S, Hwang YC, Jeong IK, Oh S, et al. Sarcopenia is independently associated with cardiovascular disease in older Korean adults: the Korea National Health and Nutrition Examination Survey (KNHANES) from 2009. PLoS One 2013;8:e60119.

8. Kim TN, Yang SJ, Yoo HJ, Lim KI, Kang HJ, Song W, et al. Prevalence of sarcopenia and sarcopenic obesity in Korean adults: the Korean sarcopenic obesity study. Int J Obes (Lond) 2009;33:885-92.

9. Cho HJ, Chang CB, Kim KW, Park JH, Yoo JH, Koh IJ, et al. Gender and prevalence of knee osteoarthritis types in elderly Koreans. J Arthroplasty 2011;26:994-9.

10. Park H, Lee SK. Association of obesity with osteoarthritis in elderly Korean women. Maturitas 2011;70:65-8.

11. Niu J, Zhang YQ, Torner J, Nevitt M, Lewis CE, Aliabadi P, et al. Is obesity a risk factor for progressive radiographic knee osteoarthritis? Arthritis Rheum 2009;61:329-35.

12. Bennell KL, Bowles KA, Wang Y, Cicuttini F, Davies-Tuck M, Hinman RS. Higher dynamic medial knee load predicts greater cartilage loss over 12 months in medial knee osteoarthritis. Ann Rheum Dis 2011;70:1770-4.

13. Varlotta GP, Lefkowitz TR, Schweitzer M, Errico TJ, Spivak J, Bendo JA, et al. The lumbar facet joint: a review of current knowledge: part 1: anatomy, biomechanics, and grading. Skeletal Radiol 2011;40:13-23.

14. O’Neill TW, McCloskey EV, Kanis JA, Bhalla AK, Reeve J, Reid DM, et al. The distribution, determinants, and clinical correlates of vertebral osteophytosis: a population based survey. J Rheumatol 1999;26:842-8.

15. Korean National Statistical Office. Population projections of Korea: 2010-2060 (based on the 2010 census). 2012 [accessed 2016 Mar 16]; Available from: URL: http://meta.narastat.kr/ metasvc/index.do?confmNo=10133\&inputYear=2011 
16. Kim DM, Ahn CW, Nam SY. Prevalence of obesity in Korea. Obes Rev 2005;6:117-21.

17. Lee CB, Lee HS, Bae SC, Choi WH. Effect of weigh reduction on the quality of life of patients with osteoarthritis and obesity. Korean J Obes 2004;13:293-9.

18. Moon SJ, Kim TH, Yoon SY, Chung JH, Hwang HJ. Relationship between stage of chronic kidney disease and sarcopenia in Korean aged 40 years and older using the Korea National Health and Nutrition Examination Surveys (KNHANES IV-2, 3, and V-1, 2), 2008-2011. PLoS One 2015;10:e0130740.

19. Heymsfield SB, Smith R, Aulet M, Bensen B, Lichtman S, Wang J, et al. Appendicular skeletal muscle mass: measurement by dual-photon absorptiometry. Am J Clin Nutr 1990; 52:214-8.

20. WHO Expert Consultation. Appropriate body-mass index for Asian populations and its implications for policy and intervention strategies. Lancet 2004;363:157-63.

21. Kim JH, Hwang BY, Hong ES, Ohn JH, Kim CH, Kim HW, et al. Investigation of sarcopenia and its association with cardiometabolic risk factors in elderly subjects. J Korean Geriatr Soc 2010;14:121-30.

22. Janssen I, Heymsfield SB, Ross R. Low relative skeletal muscle mass (sarcopenia) in older persons is associated with functional impairment and physical disability. J Am Geriatr Soc 2002;50:889-96.

23. Kim YS, Lee Y, Chung YS, Lee DJ, Joo NS, Hong D, et al. Prevalence of sarcopenia and sarcopenic obesity in the Korean population based on the Fourth Korean National Health and Nutritional Examination Surveys. J Gerontol A Biol Sci Med Sci 2012;67:1107-13.

24. Kellgren JH, Lawrence JS. Radiological assessment of osteoarthrosis. Ann Rheum Dis 1957;16:494-502.

25. Yoshimura N, Muraki S, Oka H, Mabuchi A, En-Yo Y, Yoshida $\mathrm{M}$, et al. Prevalence of knee osteoarthritis, lumbar spondylosis, and osteoporosis in Japanese men and women: the research on osteoarthritis/osteoporosis against disability study. J Bone Miner Metab 2009;27:620-8.

26. Lee S, Kim TN, Kim SH. Sarcopenic obesity is more closely associated with knee osteoarthritis than is nonsarcopenic obesity: a cross-sectional study. Arthritis Rheum 2012;64:3947-54.
27.Zheng W, McLerran DF, Rolland B, Zhang X, Inoue M, Matsuo $\mathrm{K}$, et al. Association between body-mass index and risk of death in more than 1 million Asians. N Engl J Med 2011;364: 719-29.

28. Vincent HK, Heywood K, Connelly J, Hurley RW. Obesity and weight loss in the treatment and prevention of osteoarthritis. PM R 2012;4(Suppl 5):S59-67.

29. Kalichman L, Hunter DJ. Lumbar facet joint osteoarthritis: a review. Semin Arthritis Rheum 2007;37:69-80.

30. Visser M, Pahor M, Tylavsky F, Kritchevsky SB, Cauley JA, Newman $A B$, et al. One- and two-year change in body composition as measured by DXA in a population-based cohort of older men and women. J Appl Physiol (1985) 2003;94:236874.

31. Cruz-Jentoft AJ, Baeyens JP, Bauer JM, Boirie Y, Cederholm T, Landi F, et al. Sarcopenia: European consensus on definition and diagnosis: report of the European working group on sarcopenia in older people. Age Ageing 2010;39:412-23.

32. Hughes VA, Frontera WR, Wood M, Evans WJ, Dallal GE, Roubenoff $\mathrm{R}$, et al. Longitudinal muscle strength changes in older adults: influence of muscle mass, physical activity, and health. J Gerontol A Biol Sci Med Sci 2001;56:B209-17.

33. Waters DL, Baumgartner RN. Sarcopenia and obesity. Clin Geriatr Med 2011;27:401-21.

34.Zamboni M, Mazzali G, Fantin F, Rossi A, Di Francesco V. Sarcopenic obesity: a new category of obesity in the elderly. Nutr Metab Cardiovasc Dis 2008;18:388-95.

35. Hui W, Litherland GJ, Elias MS, Kitson GI, Cawston TE, Rowan $\mathrm{AD}$, et al. Leptin produced by joint white adipose tissue induces cartilage degradation via upregulation and activation of matrix metalloproteinases. Ann Rheum Dis 2012;71: 455-2.

36. Wang ZM, Visser M, Ma R, Baumgartner RN, Kotler D, Gallagher D, et al. Skeletal muscle mass: evaluation of neutron activation and dual-energy X-ray absorptiometry methods. J Appl Physiol (1985) 1996;80:824-31.

37. Cooper C, Dere W, Evans W, Kanis JA, Rizzoli R, Sayer AA, et al. Frailty and sarcopenia: definitions and outcome parameters. Osteoporos Int 2012;23:1839-48.

38.Zamboni M, Zoico E, Scartezzini T, Mazzali G, Tosoni P, 
Zivelonghi A, et al. Body composition changes in stableweight elderly subjects: the effect of sex. Aging Clin Exp Res 2003;15:321-7.

39. Hu PF, Bao JP, Wu LD. The emerging role of adipokines in osteoarthritis: a narrative review. Mol Biol Rep 2011;38:873-8.
40. Oh HJ, Kim JH, Chung HY, Han KO, Jang HC, Yoon HK, et al. The usefulness of waist circumference as a indicator of the abdominal obesity: the risk factor of coronary artery disease. Korean J Obes 1999;8:124-9. 